\title{
THE ASSOCIATION OF PHENYLKETONURIA WITH LEUCODYSTROPHY
}

\author{
L. CROME
}

From the Fountain Hospital, London

A case of phenylketonuria presented below was associated with leucodystrophy (Schilder's disease), a combination previously observed by other workers in three older phenylketonuric patients. The present case was the oldest patient in a series of six phenylketonuric individuals coming to necropsy and examined pathologically at this hospital. None of the other patients, four of whom were reported by Crome and Pare (1960), showed similar changes. The primary object of this report is to draw attention to this association of the two conditions which may prove to be significant for the understanding of the pathogenesis and natural history of both phenylketonuria and leucodystrophy.

\section{CASE REPORT (C.B. 23/59)}

The patient's parents are healthy and normally intelligent; neither excretes phenylpyruvic acid in the urine. The patient's three siblings are also normal. One paternal uncle is a high-grade feeble-minded phenylketonuric patient in a mental deficiency hospital.

The patient weighed $9 \frac{1}{2} \mathrm{lb}$. at birth, her delivery being described as very difficult. She was born in a state of blue asphyxia and was difficult to resuscitate. Her mental and physical retardation was noticed in infancy when she began to fail to pass normal landmarks of development. She suffered from frequent respiratory infections and bouts of vomiting. Fits began in early infancy, petit mal attacks occurring about once a week and grand mal once in two or three months.

At 2 years she was admitted to the Fountain Hospital. At that time she was an adequately nourished small girl (height $78.7 \mathrm{~cm}$.; weight $10.9 \mathrm{~g}$.) with yellow soft hair and blue irides, her siblings having darker colouring. The Wassermann reaction was negative. She was a helpless idiot who cried frequently and took no notice of her surroundings.

In the course of a routine survey, when the patient was 6 years old, phenylpyruvic acid was found in the urine, about $1 \mathrm{~g}$. daily. The incisors were widely spaced. At the time her head circumference was $47.7 \mathrm{~cm}$., the average normal for the age being $50.8 \mathrm{~cm}$. with S.D. \pm 1.4 , and, as her head did not enlarge thereafter, microcephaly became in time more pronounced. A radiograph of the skull showed an abnormally steep forward rise of the floor of the anterior fossa.
An old calcified scar was present in the right lung and calcareous glands were seen in the right hilar region. The blood urea, serum phosphatase, thymol turbidity, and Van den Bergh reactions, and the serum albumin, globulin, and fibrinogen levels were all within normal limits. Two galactose tolerance tests gave conflicting results, the first indicating some liver dysfunction and the second, a few months later, being within normal limits. A liver biopsy showed only a slight excess of fat.

Although she could be induced to follow a moving object with her eyes, her attention could not be held for more than a few seconds. The pupils reacted to light and convergence. There was internal strabismus of the right eye and nystagmus when she turned her eyes laterally to either side.

Observations made in the course of years regarding her motor responses were somewhat conflicting. Some entries state that she was hypotonic in the lower limbs, and others that she was hypertonic. The plantar responses were always extensor and tendon jerks appear to have been always brisk. However, all observers agreed that her paralysis was greater than in other phenylketonuric patients and, after the age of 10 , there was definite spasticity of the legs. The question was raised whether her condition might not have been due in part to birth injury.

An E.E.G. at 10 years showed almost continuous irregular high-voltage spikes and waves. The spikes were sharper on the left side and an indefinite focus appeared to be present in the central areas. The discharges seemed to be inhibited by photic stimulation. This asymmetry suggested the possibility of a local cortical lesion in the left hemisphere.

The patient was subject to frequent respiratory infections and occasional dermatitis. Hypochromic anaemia was noted on several occasions, the haemoglobin varying from $9 \cdot 1$ to $11.5 \mathrm{~g} . / 100 \mathrm{ml}$.

A study of the serum proteins and lipoproteins at 15 years gave the following results (Dr. J. Stern):-Total serum protein $5.5 \mathrm{~g} . / 100 \mathrm{ml} .\left(\alpha_{1} 9.9 \%, \alpha_{2} 10.9 \%, \beta 14.8 \%\right.$, $\gamma 20.8 \%$, albumin $43.6 \%$ ); total serum lipids $665 \mathrm{mg} . / 100$ ml. ( $\alpha$ lipoprotein $10 \cdot 8 \%, \beta$ lipoprotein $69.9 \%, \mathrm{R} 19.3 \%$ ). $(\mathrm{R}$, the 'rest fraction', is the lipoprotein fraction which does not move from the origin when the serum is subjected to electrophoresis on paper.) It was thought that the $\gamma$ globulin was high for a phenylketonuric while the total serum albumin was low. The $\beta / \alpha$ lipoprotein ratio was also higher than is usual in phenylketonuria.

The patient died from bronchopneumonia at 16 years. 


\section{PATHOLOGICAL FINDINGS}

Necropsy was performed six hours after death. The body showed sunburn of the legs and trunk with a zone of pale skin in the 'bathing trunks' area. In spite of the smallness of the skull, the facial features were regular. There was kyphoscoliosis. A small healed tuberculous scar was present in the axillary segment of the right upper lobe and calcified glands at the right hilum. Both lower lobes were congested and showed areas of collapse and focal consolidation. Some tubular bronchiectasis was present at both bases. The left adrenal was shrunken and calcified.

\section{HISTOLOGICAL FINDINGS}

The somatic organs examined comprised the ovaries, thymus, salivary gland, pancreas, liver, lungs, adrenals, kidney, heart, pituitary, spleen, thyroid, and a dorsal root ganglion.

The lungs showed a combination of bronchopneumonia and collapse with some interstitial chronic inflammatory changes. A few foci of polymorphonuclear infiltration were present in the right adrenal cortex. The left adrenal presented a calcified and partially ossified medulla, the calcified area being surrounded by a capsule of fibrous tissue. A few necrotic foci infiltrated by polymorphs were present in the liver. Some plasma cells and lymphocytes were seen around a few of the ducts in the salivary gland. Other organs appeared normal.

CENTRAL NERVOUS SYSTEM The complete brain weighed $800 \mathrm{~g}$. and the cerebellum with the brainstem $101 \mathrm{~g}$. The pattern of the gyri was normal but there was a slight exaggeration of the downward slope of the medial aspects of the frontal lobes. The brain was symmetrical, presenting no abnormality of meninges, blood vessels, or cranial nerves.

Save for the anterior part of one frontal lobe, which was stored at $-20^{\circ} \mathrm{C}$, , the brain was fixed in $10 \%$ neutral formol saline.

When the brain was later cut into coronal blocks, it became evident that there was extensive bilateral degeneration of the white matter in the cerebrum. In some areas the altered tissue was friable, softish, and faintly granular; in others, it also showed a greyish discoloration. Later experience with stained sections revealed that not all the degenerated areas of the white matter could be detected by inspecting unprepared tissue.

The posterior half of the corpus callosum was thin. The substantia nigra showed apparently normal pigmentation. There was no visible change in the brain-stem, cerebellum, or spinal cord.
Many blocks were embedded in celloidin and paraffin and stained by the usual neuropathological methods. Frozen sections were stained for myelin by the Weil method, for fat by the Herxheimer method, and for glial tissue by the Holzer and the Hortega methods.

Naked-eye examination of sections stained for myelin confirmed at once the presence of bilateral widespread demyelination in the cerebral white matter and, as mentioned already, demyelination was also seen in areas presenting no definite change in the unprepared material. The lesions were continuous antero-posteriorly and situated in the centre of the white matter, extending almost from the anterior to the posterior cerebral poles. Peripherally, the change stopped a little short of the arcuate fibres. In the frontal lobes the area of demyelination was situated in the centre of the hemispheres; more posteriorly it occupied the upper portion of the centrum semiovale above the insula (Fig. 1), while in the parietal and occipital lobes it tended to be more marked in the lateral halves of the hemispheres. The digital matter of the gyri was unaffected, save for the occipital lobe where the superior and lateral occipital, as well as the angular, gyri showed marked demyelination extending up to the cerebral cortex only partially sparing the arcuate fibres (Fig. 2).

Histologically, the picture was fairly uniform. In preparations stained for myelin there was much devastation in the affected areas, the few remaining sheaths being truncated, beaded fragments. The axis cylinders seemed better preserved (Fig. 3). Astrocytes were hypertrophied and hyperplastic (Fig. 4), giving rise to a dense meshwork of fine fibrillary processes (Fig. 5). Some of the astrocytes were bi- or multi-nucleated and there were occasional cells in the process of amitotic division.

A considerable amount of sudanophilic material was scattered through the demyelinated areas (Fig. 6). Some of it was in the form of fine granules situated within the cytoplasm of astrocytes. However, most of the sudanophilic material lay free within the tissue as coarse, globular, or irregular particles, or was contained within compound granular corpuscles. The total amount of the sudanophil debris varied greatly from area to area, large tracts of demyelinated tissue being entirely devoid of it.

The white matter in non-demyelinated areas showed widespread vacuolation.

The cerebral cortex presented subpial fibrous gliosis, slight astrocytic hyperplasia of the molecular layer, and mild loss of cortical neurons, especially in the occipital lobe. There was no focal neuronal loss in the Sommer sector of the hippocampus.

Pigment was present in the substantia nigra and locus caeruleus, but no detailed control studies were 


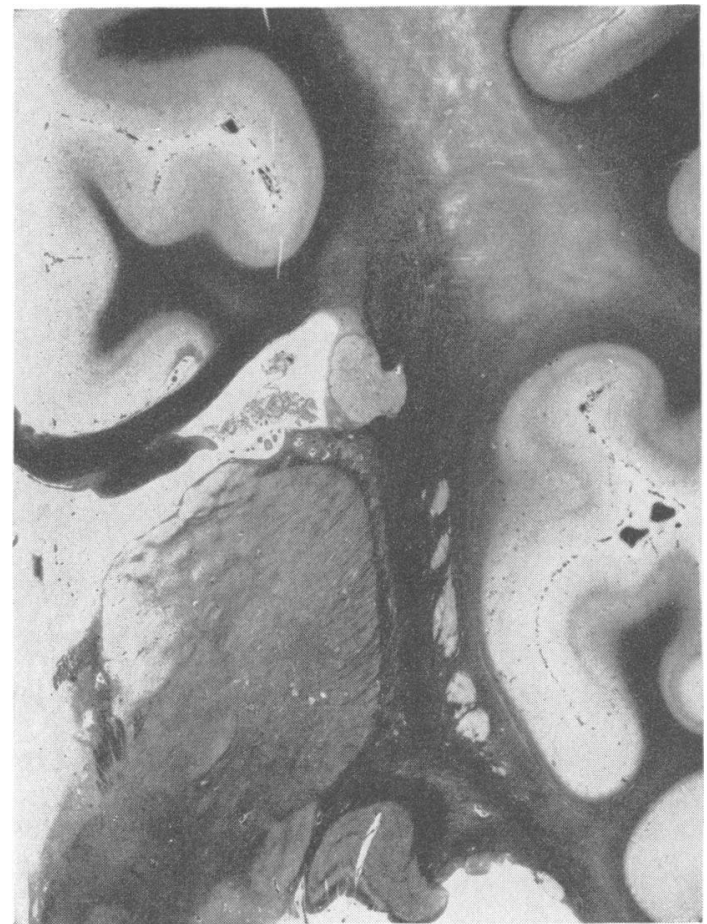

FIG. 1

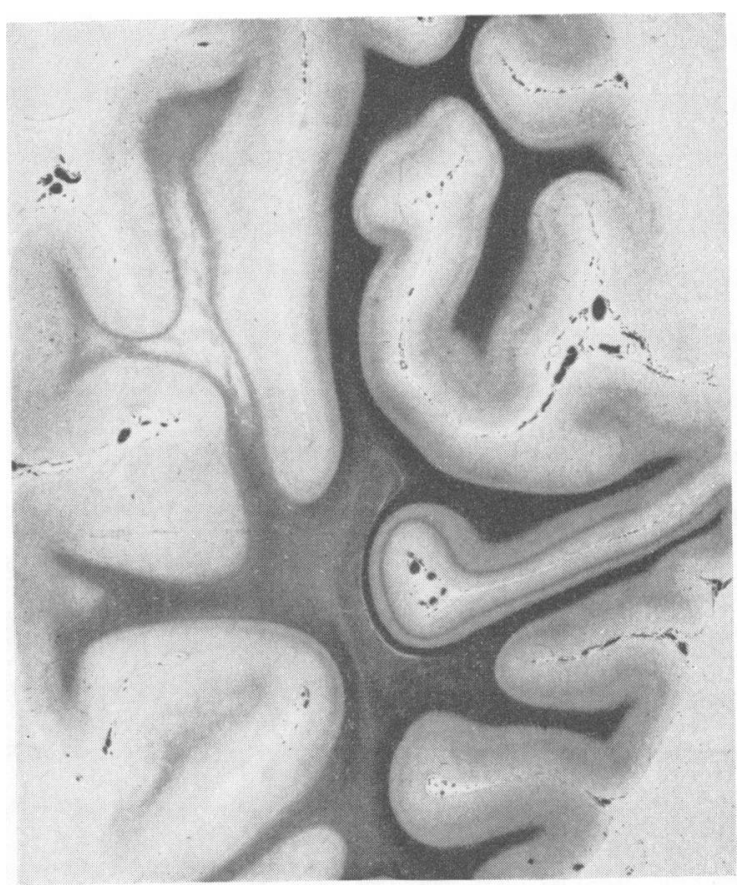

FIG. 2

FIG. 1. Demyelination of cerebral white matter above the insula. Heidenhain $\times 2$.

FIG. 2. Demyelination in central and digital white matter of the occipital lobe. The change is much more marked in the lateral half of the hemisphere. Heidenhain $\times 2$.

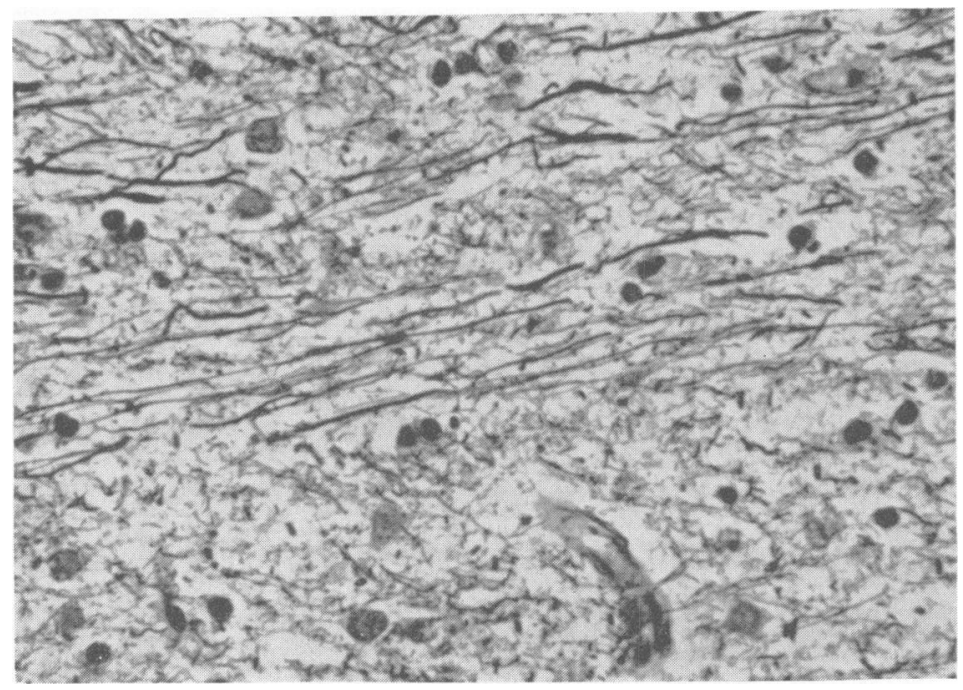

FIG. 3. Relative sparing of axis cylinders in a degenerate area of white matter. Bielschowsky $\times 400$. 


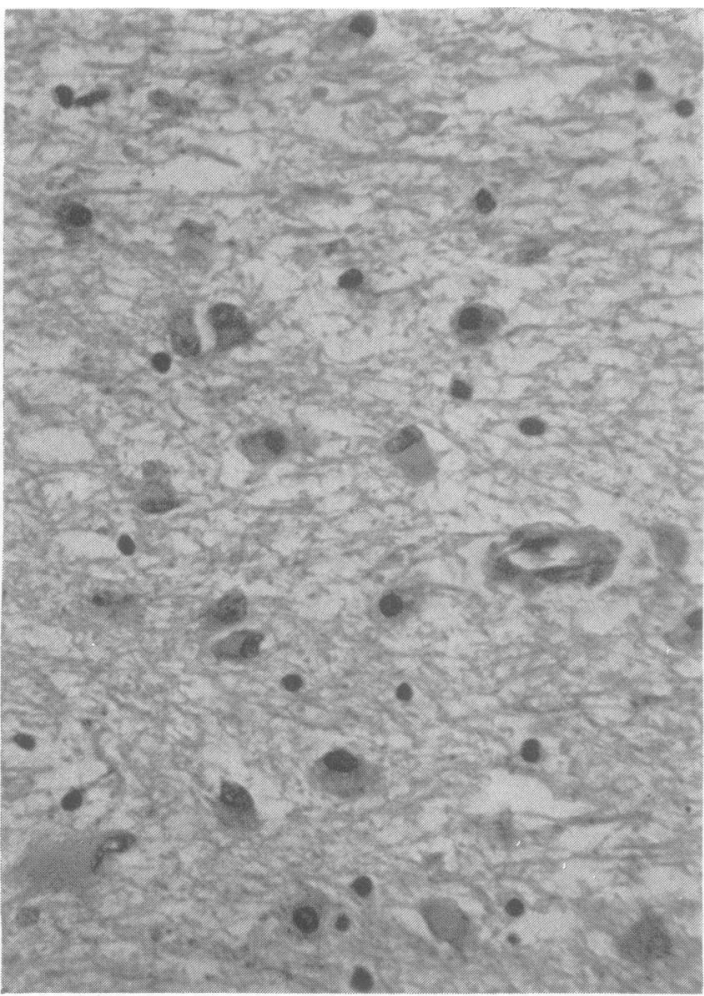

FIG. 4. Astrocytic hypertrophy and hyperplasia in the white matter. Haematoxylin and eosin $\times 400$.

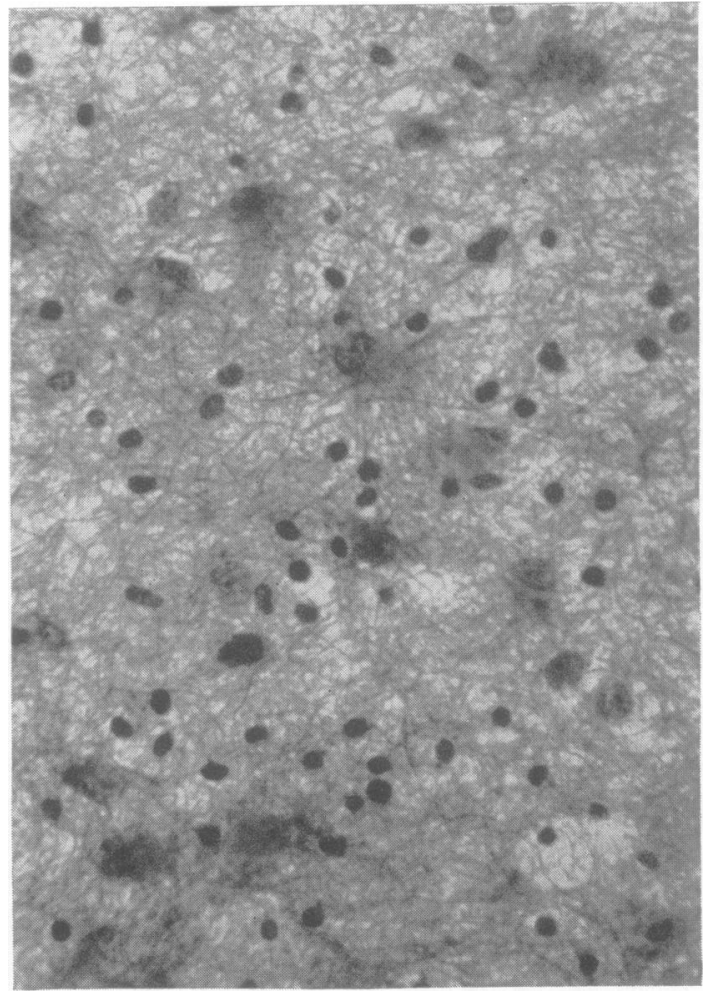

FIG. 5. Astrocytic hyperplasia with a meshwork of fine fibres. Holzer $\times 450$.

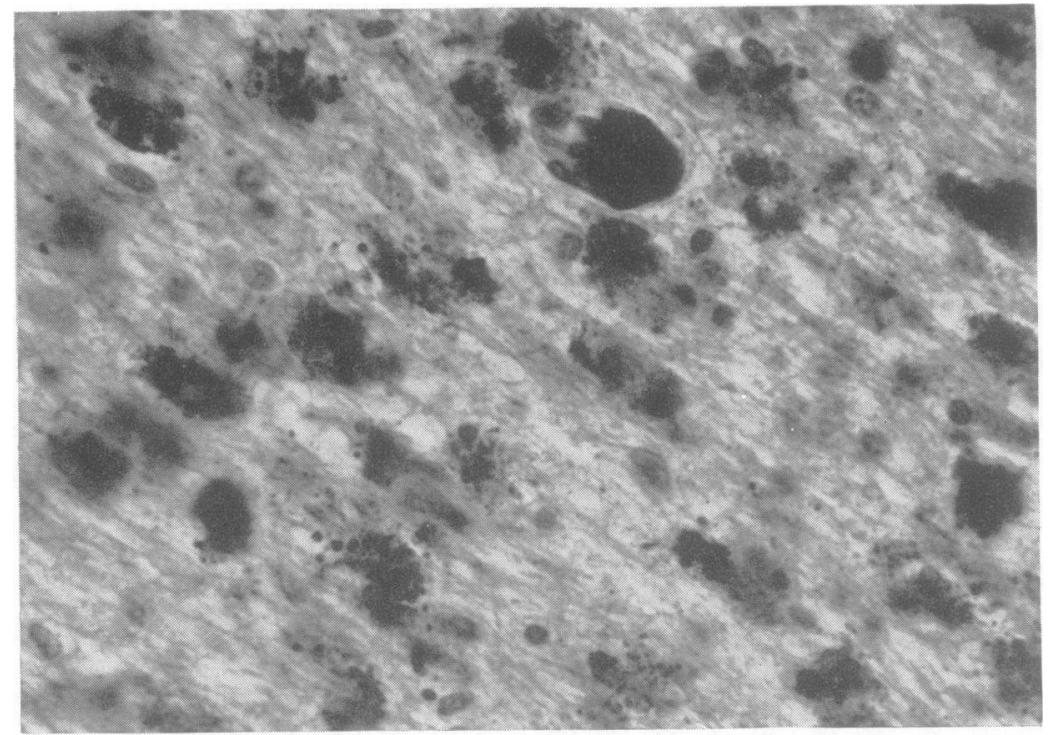

Fig. 6. Sudanophilic debris. Herxheimer $\times 450$. 
TABLE I

WATER AND LIPID CONTENT OF 'NORMAL' AND DEMYELINATING WHITE MATTER

\begin{tabular}{|c|c|c|c|c|c|c|c|}
\hline & \multirow{3}{*}{$\begin{array}{l}\text { Dry } \\
\text { Matter } \\
(\%)\end{array}$} & \multicolumn{2}{|c|}{ Cerebrosides } & \multicolumn{4}{|c|}{ Cholesterol } \\
\hline & & \multirow{2}{*}{$\begin{array}{l}\% \text { Wet } \\
\text { Weight }\end{array}$} & \multirow{2}{*}{$\begin{array}{l}\% \text { Dry } \\
\text { Weight }\end{array}$} & \multicolumn{2}{|c|}{$\%$ Wet Weight } & \multicolumn{2}{|c|}{$\%$ Dry Weight } \\
\hline & & & & Free & Ester & Free & Ester \\
\hline $\begin{array}{l}\text { Non-demyelinating white matter } \\
\text { White matter undergoing demyelination } \\
\text { Control white matter from a normal case }\end{array}$ & $\begin{array}{l}20 \cdot 4 \\
15 \cdot 8 \\
24 \cdot 1\end{array}$ & $\begin{array}{l}2 \cdot 31 \\
1 \cdot 55 \\
3 \cdot 50\end{array}$ & $\begin{array}{r}11 \cdot 3 \\
9 \cdot 8 \\
14 \cdot 5\end{array}$ & $\begin{array}{l}2 \cdot 70 \\
1 \cdot 92 \\
3 \cdot 66\end{array}$ & $\begin{array}{l}0.02 \\
0.33 \\
0.03\end{array}$ & $\begin{array}{l}13 \cdot 2 \\
12 \cdot 1 \\
15 \cdot 2\end{array}$ & $\begin{array}{l}0 \cdot 1 \\
2 \cdot 2 \\
0 \cdot 12\end{array}$ \\
\hline
\end{tabular}

undertaken and the amount of pigment may well have been deficient.

The basal ganglia were normal, save for some doubtful loss of cells and myelin fibres in the dorsomedial thalamic nucleus. There was mild focal loss of Purkinje cells with proliferation of Bergmann glia in the cerebellum. A few blood vessels in the medulla were cuffed by a ring of mononuclear cells, and there were also a few foci of neuronal necrosis with neuronophagia in the medullary tegmentum. Both in the medulla and the spinal cord myelin in the cortico-spinal pathways of the pyramids and the lateral column of the cord appeared somewhat pale.

\section{NEUROCHEMICAL FINDINGS}

The neurochemical findings in the present case and in control material taken from an individual of similar age are given in Table $\mathrm{I}$. We used the methods described by Crome, Tymms, and Woolf (1962).

\section{DISCUSSION}

The neuropathological findings in phenylketonuria have been recently reviewed by Crome and Pare (1960). Phenylketonurics usually present slight micrencephaly with reduction in the total amount of the white matter and some fibrous gliosis. Pallor of myelin, when present, is restricted to a relatively small area and is usually unaccompanied by widespread sudanophilic breakdown. However, as indicated already, frank demyelination of the white matter has been reported in three cases. Two of these were 21-year-old patients described by Benda (1952); the third, aged 25 , briefly mentioned by Jervis (1954), presented a 'curious and probably fortuitous association' with Schilder's disease.

Although few histological details are recorded with the above reports, the findings were probably similar to those in the present case. Widespread degeneration of the cerebral white matter accompanied by the appearance of sudanophilic breakdown products and astrocytic gliosis, with sparing of the cortex and arcuate fibres as in the present case, is, of course, characteristic for the so-called sudano- philic type of leucodystrophy or Schilder's disease. The neurochemical findings in the present case are compatible with those found in other phenylketonurics (Crome et al., 1962); however, in the area undergoing active demyelination, the decrease in solid matter, cerebrosides, and cholesterol below the normal is even more marked than in other parts of the white matter and is compatible with leucodystrophy.

The association of the two conditions is difficult to explain, but its presence in four out of a total of 26 cases examined pathologically can hardly be regarded as fortuitous. Future experience will probably show whether the damage to the white matter may be, at least partially, ictal in origin. Moreover, both phenylketonuria and leucodystrophy are transmitted in a genetically recessive manner, and it is possible that some aspects of metabolic anomaly are common to the two conditions.

\section{SUMMARY}

Attention is drawn to the occasional association of phenylketonuria and leucodystrophy (Schilder's disease) in older phenylketonuric patients. A new example of this association in a girl aged 16 at the time of death is presented. The true incidence of this association is not known, but it was present in four out of 26 recorded cases examined pathologically. This rate of association of two uncommon diseases is unlikely to be fortuitous.

I wish to thank my colleagues at the Fountain Hospital for access to the case records and for their helpful criticism of this paper. Miss S. Mallen, Mrs. V. Tymms, and Dr. L. I. Woolf have done the neurochemical studies and have kindly permitted me to quote their results.

\section{REFERENCES}

Benda, C. E. (1952). Developmental Disorders of Mentation and Cerebral Palsies, p. 451. Grune \& Stratton, New York.

Crome, L., and Pare, C. M. B. (1960). J. ment. Sci., 106, 862.

-, Tymms, V., and Woolf, L. I. (1962). J. Neurol. Neurosurg. Psychiat., 25, 143.

Jervis, G. A. (1954). "Phenylpyruvic oligophrenia (Phenylketonuria)" in Genetics and the Inheritance of Integrated Neurological and Psychiatric Patterns (Res. Publ. Ass. nerv. ment. Dis., 33), p. 259. Williams \& Wilkins, New York. 